\title{
Brentano on intentionality
}

\author{
Tim Crane
}

Brentano's account of what he called intentionale Inexistenz — what we now call intentionality is without question one of the most important parts of his philosophy, and one of the most influential ideas in late $19^{\text {th }}$-century philosophy. Here I will explain how this idea figures in Brentano's central text, Psychology from an Empirical Standpoint (Brentano 1995a). I will then briefly explain how Brentano's ideas about intentionality evolved after the first publication of this work in 1874 , and how they were then misinterpreted by some influential analytic philosophers.

The Psychology is in no sense a finished work, and the text that was translated into English in 1973 has a somewhat complex history and structure. Brentano originally planned a six-volume work. The first two volumes, published together in 1874, form the bulk of what has been passed down to Anglophone readers in the 1973/1995 edition (Brentano 1995a). These are Book One, 'Psychology as a Science', and Book Two, 'Mental Phenomena in General'. Three further volumes were planned on each of the fundamental categories of mental phenomena - presentation, judgement and the phenomena of love and hate (see CHAP. 9) - and the work was to be concluded by a final volume on the immortality of the soul and the mind-body relation. But these last four volumes, were never published, though the third exists in draft form.

In 1911, part of Book Two was published under the title Von der Klassifikation der psychischen Phänomene ('On the Classification of Mental Phenomena') along with a substantial appendix, in which Brentano developed some of his ideas and indicated some changes of mind. After Brentano's death in 1917, his follower Oskar Kraus produced a second edition of the Psychology, published in 1924, which included the appendix from the 1911 book plus some further supplementary essays from Brentano's unpublished writings. The English edition published by Routledge and Kegan Paul in 1973 was the work of three translators: Linda L. McAlister, Antos C. Rancurello, and D.B. Terrell, with McAlister in charge. The translation was based on Kraus's 1924 
edition, and so included not only the appendix and supplementary essays, but also Kraus's footnotes, which attempt to explain Brentano's ideas. These are marked in the English text by numbers, whereas Brentano's footnotes are indicated by asterixes and other footnote symbols. Kraus's footnotes are of some historical interest, but they are not always entirely accurate in their exposition of Brentano's views, and so must be approached with care. The supplementary material in the appendices, however, contains many philosophical insights, and provides a valuable guide to the ways in which Brentano's thought developed after 1874.

But we must begin with the core of Brentano's thinking: the conception of intentionality in his 1874 work. What was Brentano's overall picture of the mind, and what was the role of the concept of intentionality in this picture? One central aim of the Psychology was to establish psychology as a science distinct from philosophy on the one hand, and physiology on the other. Psychology is a science whose data come from experience and introspection - hence this is psychology from an empirical standpoint.

It's important to recognise the difference between this use of 'empirical' and the contemporary conception of psychology as an empirical science. From today's intellectual perspective, to say that psychology is an empirical science implies that it uses the kinds of methods (e.g. quantitative or statistical methods) which are characteristic of the other natural sciences. From that perspective, Brentano's introspective psychology is no more empirical than William James's. (I ignore here the distinction Brentano makes between descriptive and genetic psychology; see CHAP. 3.) But Brentano's use of the word 'empirical' is supposed to indicate that psychology must be based on experience: 'experience alone is my teacher', as he says in the foreword to the Psychology. From his reflections on experience, Brentano aimed to outline the distinction between psychology and other sciences.

Brentano believed that to make this distinction, there must be a criterion which distinguishes its subject-matter from the subject-matter of physical science. In Book One of the Psychology Brentano had defined psychology as the 'science of mental phenomena', opposing the etymologically more precise definition of it as the 'science of the soul'. To understand what Brentano meant by his definition, we have to understand 'phenomena' and 'mental'.

In the tradition in which Brentano is writing, 'phenomenon' means appearance. Broadly speaking, phenomena or appearances are typically contrasted, in various ways, with reality. In the 
most famous version of this contrast, Kant contrasted phenomena with noumena, or 'things in themselves'. Brentano was an Aristotelian rather than a Kantian, but the emphasis on science's relationship to phenomena rather than things in themselves is nonetheless central to his philosophy. Throughout the first chapter of the Psychology, Brentano clearly distinguishes between 'that which really and truly exists' and appearances or phenomena. He did think there is an underlying reality behind the phenomena, but this cannot be what he calls an 'object of science'. Science can only study phenomena. Before we examine what makes a phenomenon mental, we should say something about this use of the terms 'phenomenon' and 'science'.

These two terms should really be understood together. As we have seen, Brentano believed that natural science does not uncover the real nature of things. In particular, physics is not the science of bodies because even if we can be said to encounter the properties of bodies, "we never encounter that something of which these things are properties' (1995a: 11). All that science can ever discover are the appearances of things: these are the 'physical phenomena' like 'light, sound, heat, spatial location and locomotion'. As Brentano puts it, 'what are physical phenomena if not the colours, sounds, heat and cold etc., which manifest themselves in our sensations?' (1995a: 69).

Science studies phenomena; that is all that science can do - even if there is an underlying reality behind the phenomena. The differences between sciences reduce to the differences between the phenomena studied by the sciences. The distinction between psychology and physics therefore reduces to the distinction between mental and physical phenomena. It is crucial for understanding Brentano's Psychology that this distinction is a distinction among the 'data of consciousness' (1995a: 77) and not among entities as we would conceive them in a realist metaphysics. Brentano talks approvingly of Lange's idea of 'psychology without a soul' (1995a: 11). What he means here is that psychology can proceed while being indifferent on the question of whether there is a soul: for 'whether or not there are souls, there are mental phenomena' (1995a: 18).

Phenomena or appearances are, in a certain way, mind-dependent. However, to say that all phenomena are mind-dependent does not mean that all phenomena are mental. So what, then, are mental phenomena? Brentano's answer to this question is the source of his famous doctrine that 'intentional inexistence' is the distinguishing mark of mental phenomena. In the most famous passage in the book, he writes: 
Every mental phenomenon is characterised by what the Scholastics of the Middle Ages called the intentional (or mental) inexistence of an object, and what we might call, though not wholly unambiguously, reference to a content, direction toward an object (which is not to be understood here as meaning a thing) or immanent objectivity. Every mental phenomenon includes something as an object within itself, although they do not all do so in the same way. In presentation, something is presented, in judgement something is affirmed or denied, in love loved, in hate hated, in desire desired, and so on. (Brentano 1995a: 88)

This complex passage has given rise to much philosophical discussion; here we can start by identifying the key elements of Brentano's terminology. The 'object' of a mental phenomenon is what it is directed on. 'Intentional inexistence' does not have anything to do with the possible or actual non-existence of the object of a mental act; rather, it means that the object 'exists in' the mental phenomenon itself. Brentano's introduction of the terminology of intentional inexistence does not appeal to, and nor does it presuppose, any distinction between existent and non-existent objects of thought. That is not the issue.

Since there has been much confusion about this terminology it is worth dwelling a little on the difference between Brentano's assumptions and the typical assumptions of today's analytic philosophy. These days the problem of intentionality is introduced against the background of a 'commonsense' realism which assumes a realm of ordinary objects which exist independently of our minds, that relations hold between such objects, and that science studies these objects. I have already stressed that this is not Brentano's starting point. As Barry Smith has nicely put it, 'one will find no coherent interpretation of Brentano's principle of intentionality so long as one remains within the framework of our usual, commonsensical notions of both the mind and its objects' (1994: 40). In particular, Brentano's original 1874 doctrine of intentional inexistence has nothing to do with the problem of how we can think about things that do not exist. Although his account of intentionality would certainly yield an account of thought about, say, Pegasus, this is only because it is an account of thought in general, and not because Pegasus was what was motivating the account.

The other terms he uses, 'relation to a content', 'immanent objectivity' are verbal alternatives to 'intentional inexistence'. Content and object are the same thing for Brentano, and the 'objectivity' of mental phenomena is just a matter of them having an object. The object is immanent in the sense that it is 'in' the mental act itself, as an Aristotelian form is immanent in a substance, unlike 'transcendent' Platonic forms, which belong outside of the world of experience.

As Smith comments, the thesis that 'every mental phenomenon includes something as object within itself' is 'to be taken literally - against the grain of a seemingly unshakeable tendency to 
twist Brentano's words at this point' (Smith 1994: 40). So, taken literally, the intentional inexistence of an object really does mean its existence in the mental act itself. The phenomena on which a mental act is directed may be physical or mental. In the former case, a mental act has as its object something like a sound or a shape or a colour. In the latter case, a mental act would have as its object another mental act. For example, one may think about the mental act of hearing a sound. But whether physical or mental, the objects of acts are still phenomena and hence, it is important to emphasise, fundamentally mind-dependent. Brentano was not, therefore, proposing an account of how we think about mind-independent 'external' objects. This is because, according to his methodological phenomenalism, the phenomena, which are the only objects for science, are not 'external' objects. Physical phenomena have underlying causes, but these underlying causes are not the objects of science. (More later on the notion of 'methodological phenomenalism'.)

The background to Brentano's view is partly Aristotelian, as Brentano indicates in a wellknown footnote (1995a: 88). Aristotle had talked in De Anima about how in perception, the perceiving organ takes on the 'form' of the perceived object: in seeing something blue, the eye takes on blueness without taking on the matter of blueness. Brentano, like Aquinas, wanted to follow Aristotle in at least this respect: the proper objects of thought and perception - what it is that we are thinking of, and what makes thought possible at all - are actually immanent in the act of thinking, and do not transcend the mental act. In this respect, objects of thought may be compared to universals on an Aristotelian conception of them, according to which they are immanent in the particulars which instantiate them, and do not transcend those particulars.

In his illustration of his doctrine of intentional inexistence in the famous quotation, Brentano uses these examples: in presentation, something is presented, in judgement, something is judged, and in love something is loved. These examples correspond to Brentano's division of mental phenomena into three fundamental classes (1995a: Book Two, Chapter VI). These are the classes of (1) presentations, (2) judgement, and (3) phenomena of love and hate (which for Brentano includes desire). This classification is original to Brentano, as he himself observes, and a few remarks are necessary in order to elucidate Brentano's conception of the mind.

The word which is normally translated here as 'presentation' is Vorstellung, a word with a rich philosophical history and many connotations. English translations of Kant typically render it as 'representation'. The standard translation of Gottlob Frege's famous paper, 'The Thought' translates Vorstellung as 'idea' (Frege 1920). Frege distinguished there between thoughts (Gedanken), which 
are objective, mind-independent bearers of truth and falsehood, and ideas, which are subjective, mind-dependent and do not serve as the locus of objective truth. 'Idea' is sometimes used by Brentano's translators; but it is not always a good term for what he meant, since (like 'thought') the English word is more naturally used for what a subjective state is directed on (its content or object), rather than the state itself. Ideas in the ordinary sense can be discussed impersonally — in an encyclopaedia or dictionary, for example - whereas a Vorstellung is meant to be something particular to an individual at a given time. As Brentano puts it: "by "presentation" we do not mean that which is presented, but rather the presenting of it' (1995a: 79).

Presentation, for Brentano, is the fundamental way of being conscious of an object: all other mental phenomena involve presentations, and therefore all mental phenomena are conscious. Judgement, the second fundamental class of mental phenomena, always involves presentation of an object, but this is distinct from the conscious act of judging itself. When one judges $\mathrm{X}, \mathrm{X}$ is before one's mind in two ways: as the object of the presentation, and as the object of judgement. Brentano's conception of judgement, however, is very different from the conception of many 20th century philosophers. Those philosophers who take their lead from Frege, G.E. Moore or Bertrand Russell, for example, treat judgement as a relation to a proposition: the kind of thing expressible in a sentence, assessable as true or false. Brentano's theory does not contain propositions, and took all judgement to involve affirming or denying the existence of something (see CHAP. 10). To judge that it is raining, for example, is to affirm (or better, acknowledge) the existence of rain.

The third main category of mental phenomena, which Brentano calls 'the phenomena of love and hate', incorporates not just emotions but also acts of will and desire. These phenomena also involve presentation, as every mental phenomenon does, but also involve some kind of motivational or affective attitude to the object of the presentation. Much of Book Two of the Psychology is concerned with articulating the distinction between the three kinds of mental phenomena (see Mulligan 2004 for a useful discussion).

Two other features of presentation are worth noting here. First, a presentation may be inner or outer. An inner presentation may be a feeling or an awareness of some mental act; the objects of inner perception are thinking, feeling and willing. The objects of outer presentation or perception are warmth, colour, sound and so on (i.e. physical phenomena). A distinctive feature of his view is that every mental act is also directed on itself (although in what Brentano called a 'secondary' sense) as well as on its primary object. Second, in the 1874 book Brentano held that every mental 
activity involves an emotional or affective element, but he later came to abandon this view and to hold instead that some sensations have no such element. He makes clear tis change of mind in the 1911 edition of selections from the Psychology (1995a: 276).

The picture of Brentano's 1874 views which I have sketched here is in some ways foreign to contemporary discussions of intentionality, which, as noted above, tend to assume a commonsense realism about the material world, often accompanied by a physicalist conception of the findings of science. But placed in wider context, the views should not be so strange. For Brentano's conception of science has a lot in common with the kind of phenomenalism which was common in $19^{\text {th }}$-century philosophy of science, which survived into the $20^{\text {th }}$ century in logical positivism, and which has echoes in W.V. Quine's claim that the purpose of science is to explain and predict the course of experience. At the beginning of the Psychology, Brentano mentions Mill approvingly as 'one of the most important advocates of psychology as a purely phenomenalistic science' (1995a: 14), and he expressed sympathy with Ernst Mach's phenomenalism on a number of occasions (cf. Smith 1994: $41, \mathrm{n} .8)$.

Brentano was not a phenomenalist, because phenomenalism holds that the world is constructed from phenomena (e.g. sense-data). Yet as we saw, Brentano did believe that there is a world which transcends the phenomena; physical phenomena are 'signs of something real, which, through its causal activity, produces presentations of them' (1995a: 19). This is what distinguishes Brentano from phenomenalism proper: he believes that there is something beyond the phenomena, although we can never know it through science. As far as science is concerned, though, phenomenalism might as well be true. Peter Simons has helpfully labelled Brentano's view methodological phenomenalism (1995: xvii).

By the time the 1911 book came out, Brentano had changed his mind on a number of important issues. In the Preface to this 1911 edition, describing the ways in which his views had evolved, Brentano wrote that 'one of the most important innovations is that I am no longer of the opinion that mental relation can have something other than a thing as its object' (1995a: xxvi). This is Brentano's 'reism', the idea that only concrete particular things are the objects of thought (see CHAP. 16). This was a departure from the view expressed in the 1874 version, which allowed things belonging to many different ontological categories to be objects of thought. 
Another way in which his view changed was his rejection of the idea that all mental activity involves a genuine relation to an object. In the supplementary remarks published in the 1911 book, he writes:

What is characteristic of every mental activity is, as I believe I have shown, the reference to something as an object. In this respect, every mental activity seems to be something relational.... If I take something relative from among the broad class of comparative relations, something larger or smaller for example, then, if the larger thing exists, the smaller one must exist too. If one house is larger than another house, the other house must also exist and have a size.... It is entirely different with mental reference. If someone thinks of something, the one who is thinking must certainly exist, but the object of his thinking need not exist at all.... For this reason, one could doubt whether we are really dealing with something relational here, and not, rather, with something somewhat similar to something relational in a certain respect, which might therefore be called 'quasi-relational'. (1995a: 272)

This is a clear departure from the relational conception of intentionality advanced in 1874, and shows similarities with the realist conception of intentionality and intentional objects famously defended by Edmund Husserl in his Logical Investigations (1901). Husserl had argued there that although we might say that the non-existent intentional object of a mental act (e.g. the god Jupiter) has 'mental inexistence' in the act, the truth of the matter is that this 'immanent, mental object' is not 'really immanent or mental. But it also does not exist extramentally, it does not exist at all' (Husserl 1901: V, §11). The object of thought, existent or not, transcends the mental act. And the mental act is not essentially constituted by the relation to the object. For Husserl, as for Brentano after 1911, the mental act cannot be relational but only 'quasi-relational' (Relativliches).

So what are these non-existent objects of thought? Later in the supplementary remarks, Brentano writes that

all mental references refer to things. In many cases, the things to which we refer do not exist. But we are accustomed to saying that they then have being as objects. This is a loose use of the verb 'to be' which we permit with impunity for the sake of convenience, just as we allow ourselves to speak of the sun 'rising' and 'setting'. (1995a: 291)

Brentano does not allow himself to follow his student Alexius Meinong (1910) and his 'theory of objects', which aimed to investigate intentional objects regardless of their existence. Talk of there 'being' such objects Brentano saw as a kind of loose talk; all it really means is that a thinker is representing something (1995a: 291).

Brentano's influence on the Phenomenological school founded by Husserl is well-known. It took a little longer for his ideas to be introduced into analytic philosophy. This can largely be 
credited to Roderick Chisholm, who was unusual among mainstream American philosophers of the time in having an active interest in Phenomenology, and published various things in the 1950s which took inspiration from Brentano (see CHAP. 44). Chisholm's work, though valuable in itself, has led to a number of persistent misunderstandings of Brentano in the analytic tradition. His famous paper, 'Sentences about Believing' (Chisholm 1955-6), for example, attempted to reformulate Brentano's criterion as a way of distinguishing between sentences describing mental phenomena and sentences describing physical phenomena, and of demonstrating the irreducibility of the mental to the physical, and hence the falsity of physicalism.

The criteria Chisholm came up with were in fact criteria for non-extensional linguistic contexts, usually known as intensional contexts: the failure of truth-functionality, the failure of substitution of co-referring terms to preserve truth-value, and the failure of existential generalisation. (On the relation between intentionality and intensional contexts, see Crane 2001 Chapter 1, and Searle 1983 Chapter 1.) But Brentano's distinction was not a distinction between linguistic contexts, and the idea that the mark of mental phenomena may be captured in this way is totally foreign to the project of his Psychology. Moreover, Brentano did not use his criterion to refute physicalism. Nonetheless, analytic philosophers persisted for a few decades in associating Brentano's ideas with Chisholm's, which only obstructed the proper understanding of Brentano.

A striking example of this can be found in W.V. Quine's Word and Object (1960). In a famous and influential discussion of intension and meaning, Quine makes two claims about Brentano. The first is that "the Scholastic word "intentional" was revived by Brentano in connection with the verbs of propositional attitude and related verbs ...- "hunt", "want" etc.'. The second is that 'there remains a thesis of Brentano's, illuminatingly developed of late by Chisholm, that ... there is no breaking out of the intentional vocabulary by explaining its members in other terms' (Quine 1960: 219). As should be obvious from what I have said so far, both these claims are false. First, Brentano did not revive the Scholastic word 'intentional' to describe propositional attitude verbs, since as we saw, Brentano did not believe in propositional attitudes in anything like the $20^{\text {th }}$-century sense. (Curiously, the example of 'hunt' is from Quine's own work (1956), not from Brentano's; and nor could it be since hunting is not a mental phenomenon.) Second, Brentano's thesis of the irreducibility of the intentional was not a claim about whether one can break out of the intentional vocabulary. It was not a claim about vocabulary at all: it was a claim about the categorial distinction between mental and physical phenomena. The natural conclusion to 
draw from this is that Quine had never read Brentano, but took the description of his views wholesale from Chisholm.

Quine's main concern was not, of course, the interpretation of Brentano, but the theory of meaning. However, Word and Object was an influential book, and inevitably the misunderstandings embodied in these casual remarks spread like diseases. To take just one example: in a famous paper, 'Mental Events', Donald Davidson proposed a 'test of the mental' according to which the mental's distinguishing feature is that 'it exhibits what Brentano called intentionality'. He explains this by saying that "we may call those verbs mental that express propositional attitudes like believing, intending, desiring, hoping, knowing, perceiving, noticing, remembering, and so on' (Davidson 1980: 211). Here again we find mixed up with a real thesis of Brentano's — that intentionality is the mark of the mental — the idea that intentional verbs are those that express propositional attitudes. Brentano's thesis was about phenomena, not about verbs. And none of the mental phenomena in Brentano's three categories — presentation, judgement and emotion — are propositional attitudes. Indeed, the notion of a propositional attitude itself was only introduced into philosophy some thirty years after Brentano's Psychology was first published, in a 1904 paper by Bertrand Russell ('belief is a certain attitude towards propositions, which is called knowledge when they are true, error when they are false' (Russell 1904: 523)). Neither the term 'propositional attitude' nor the concept were current when Brentano wrote his Psychology; Davidson's association of the idea with Brentano is as anachronistic as it is incorrect.

The problem here is not simply a failure in scholarship. It has also led to a misconception of the subject-matter itself. The association of the idea of intentionality with the logical properties of certain verbs took years to break. In recent years, rather than simply relying on Chisholm, Quine and Davidson, analytic philosophers have been reading Brentano's actual texts for themselves, and finding inspiration in them for new developments in the study of intentionality and consciousness. There is reason to be optimistic that a better understanding of Brentano's idea of intentionality is now emerging from this work. ${ }^{1}$

\section{References}


Chisholm, R.M. (1955-6) 'Sentences about Believing,' Proceedings of the Aristotelian Society 56: $125-148$

Crane, Tim (2001) Elements of Mind (Oxford: Oxford University Press)

Davidson, Donald (1980) 'Mental Events' in Essays on Actions and Events (Oxford: Oxford University Press) 79-101

Frege, Gottlob (1920) ‘The Thought', A. and M. Quinton (trans.) Mind 65 (1956): 289-311

Husserl, Edmund (1901), Logical Investigations translated by J.N. Findlay, edited by Dermot Moran, London: Routledge 2001.

Meinong, Alexius (1910) On Assumptions J. Heanue (trans.) (Berkeley: University of California Press 1983)

Mulligan, Kevin (2004) 'Brentano on the Mind' in Dale Jacquette (ed.) The Cambridge Companion to Brentano (Cambridge: Cambridge University Press) 66-97

Quine, W.V.O. (1956) ‘Quantifiers and Propositional Attitudes’ The Journal of Philosophy 53: 177187

Quine, W.V.O. (1960) Word and Object (Cambridge, MA: MIT Press)

Russell, Bertrand (1904) 523 'Meinong’s Theory of Complexes and Assumptions’ Mind 13: 509-24.

Searle, John (1983) Intentionality (Cambridge: Cambridge University Press)

Simons, Peter (1995) 'Introduction’ to Brentano (1995a)

Smith, Barry (1994) Austrian Philosophy LaSalle, Il. \& Chicago: Open Court

\footnotetext{
${ }^{1}$ Thanks to Uriah Kriegel for very helpful comments, and to Dan Brigham for discussion of the propositional attitudes. This paper was written with the help of a grant from the John Templeton Foundation, New Directions in the Study of the Mind.
} 